make possible honest disagreement between well-trained men. The easy inferences are that medicine is mere guess-work, or that doctors are hypocritical and venial. If the proposal to make medical experts an impartial special jury, summoned and paid by the court itself, can be carried out, there will be a gain for the prestige of the profession. It is to be hoped, too, that the conviction of the poor that they are regarded as mere clinical material for human vivisection may be gradually removed. This persistent misconception plays some part in the prejudice against medical men. Obviously the profession suffers seriously, not only from the quacks and charlatans without the pale, but from the self-seeking and disloyal who violate the spirit while they cleverly keep within the technical rules of the medical fraternity. By playing on the ignorance of patients, by prolonging the period of treatment, by prescribing futile remedies and advising unnecessary operations, by extortionate charges, these men do untold damage to the profession and furnish just grounds for popular distrust and resentment. The medical élite must have the vigilance and courage to protect itself, not only against enemies without, but against traitors within. Again, it is possible, with some show of truth, to charge the doctors with being slow to recognize new knowledge and better methods. There are extremists who insist that the profession has always opposed progress. The injustice of so sweeping an assertion does not prevent its having a certain effect on public opinion. The industrious incompetence of large numbers of practitioners who, graduated from preposterous schools and admitted to practice by ridiculous boards of examiners, rum their devastating careers in some of our states, does not deceive all who know them. Even if the public is undiscriminating enough to put all doctors into one class, it is not wholly to be blamed for regarding the entire group with a good deal of suspicion and derision.

Thus the more or less expert few face the many who trust individuals, but are slow to recognize the authority of the profession. What are the possibilities of reaching a better understanding? The answers are obvious: The few must deserve and win popular confidence; the many must learn to appreciate the competence and devotion of the few. And the state must formulate and enforce the terms of this better understanding. If the cure for democracy is more democracy, the corrective of a little education is more education. The only alternative is a return to autocracy. To the millenium-chaser, the shortcut reformer and the efficient administrator, the slow process of education is an irritating suggestion. They object to having their "feet always in the water."

But scientific men should face facts as they are. The public mind is like a force of nature. It is childish to rail at it, to denounce it, to expect it to be docile about technical matters. Doctors should diagnose the public calmly and in the scientific spirit. They should try to trace the play of cause and effect, and then take measures to bring desired results to pass. In this they have the right to ask the cooperation of all thinking men and women. The public is controlled by leaders. These leaders must be informed and intelljgent. 'Colleges and universities have a responsibility to train these leaders. Every institution of higher education should be a model of public sanitation and hygiene. Every graduate should be well grounded in the principles of personal and community health. The public schools could do much more than they are doing at present to train children in hygienic habits and in intelligent deference to sanitary regulations. Popular literature, lectures, parents' meet- ings, visiting nurses' associations, organizations like the antituberculosis societies, city and state health departments and boards-agencies of many kinds are all engaged in the work of popular health education. Would that Mr. Carnegie's next ten million dollar gift might be devoted to publishing in .newspapers authoritative advertising bulletins on hygiene and sanitation! Many an editor would be glad to be freed from irksome slavery to the patent medicine men.

A large responsibility for the education of the public must fall on members of the medical profession. Doctors and professors of medicine must devote some time to public addresses, to cooperation with public school authorities, to participation in local movements for improved sanitation, to hearty support of local health authorities when these are reasonably competent, and to civic movements designed to improve a defective public health service.

There is much platitudinous talk about legislation and public opinion. On the one hand are the doctrinaires whose one idea of social progress is to get some law passed. At the other extreme are to be found those who are so convinced that law unsupported by public opinion is futile, that they are in danger of neglecting legislative aid. As a matter of fact, oftentimes agitation for legislation is in itself a valuable means of public enlightenment. In any event the gains in public opinion should always be fixed as soon as possible in well-drawn laws. Movements, therefore, for legislation affecting medical education, admission to the practice of the profession, the organization of health boards, the enactment of sanitary regulations, etc., should all be regarded as a part of the process by which the expert few and the many are to be brought into relations of mutual respect and good will.

But it remains true that in a democracy, back of the coercive power of the law there lies the social authority which in the long run is vested in the few who by their approved competence and by their spirit of social service command the confidence and respect of the public. With increasing intelligence the many learn to protect themselves against quackery and to place confidence in tested leadership. If the raft of democracy cannot be transformed into a swiftly sailing ship, there is hope, at least, that it may be built up far enough above the waves to carry its passengers dry-shod.

\section{PELLAGRA TREATED WITH SALVARSAN (606)}

CHARLES M. NICE, M.D.,

JAMES S. MCLESTER, M.D., AND GASTON TORRANCE, M.D.

$$
\text { BIRMINGHAM, ALA. }
$$

In the light of early and material improvement of symptoms in three typical cases of pellagra following the administration of salvarsan, it has appeared wise to make this preliminary report. The final results, deductions, photographs and later cases will be embodied in a future report.

CASE 1.-History.-W. H. R., aged 43 , white, is an electrical engineer. The patient's family history is negative, except that one sister died some years ago of tuberculosis. The patient had malaria and rheumatic arthritis in youth. Since, he has enjoyed good health until the present condition began. About the middle of January, 1911, the patient was suddenly seized with cramping pains in his abdomen, followed by a profuse and weakening diarrhea. This persisted and did not yield to treatment. Some days later he noticed that his liands were burned to the elbows, which he attributed to hot 
oil. No similal burn ever occurred, though his work had remained the saule. Tliere was also a burn on his thigh, due "to a rent in his trousers." The patient was nervous and cried over small matters. His mouth became sore and he lost weight rapidly. He was confined to bed six weeks.

Examination.-March 4, 1911. The patient was about 5 feet, 7 inches tall, was greatly emaciated and weighed 100 pounds. His expression was dull and be answered questions sluggishly, Pupillary reflexes were normal; tongue red, moist and patchy; lungs were negative; liver two inches below costal margin; abdomen tender; patellar reflex exaggerated. There was a brownish indurated lesion of the skin over the lands and thick crusting over the points of the elbows. The intermediate forearms were pigmented, with paler areas of desquamation. There was also a large encrusted area on the inside of the thigh and the feet were somewhat involved. The wrine contained albumin and a few granular casts. The blood showed 6,000 whites, $3,225,000$ reds, 70 per cent. hemoplobit. The stools were six to eight a day, foul, containing macroscopic blood. There were no amebas, hook-worms or other important findings. Von Pirquet and Wassermann tests vere negative. The pulse was 108 to 116 ; temperature slightly subnormal.

Treatment and Course.-After observing the patient two lays, and the case being a frank one, it was decided to administer salvarsan (606), which was done by the intravenous method in a $0.5 \mathrm{gm}$. dose on March 6. There was a rise of temperature to $99.2 \mathrm{~F}$. that evening. Aside from being restless, there was no inconvenience. The following day, the patient said he was better; the bowels had moved only once in twenty-four hours.

March 8, the patient was sitting up in bed and said he was hungry; did not cry when spoken to and looked brighter.

March 9, pulse lowered to 96 . The patient knew he felt better. The skin condition had materially faded. The legs showed only a brownish discoloration; exfoliation from the hands marked.

March 12, improvement continued; practically all local signs of the disease had disappeared.

March 15, patient was walking around the ward; had gained weight; said he felt fine and was very hungry. He went lome and will return for observation.

CASES 2 and 3.-March 7 and 8, two female negroes, with well-marked pellagra and giving negative Wassermann reactions, were given, intravenously, $0.5 \mathrm{gm}$. and $0.6 \mathrm{gm}$. of salvarsan, respectively. An improvement was noted in fortyeight hours.

After a week had elapsed the skin lesions had changed marerially as had the ptyalism, vaginitis, weight and mental symptoms. Both were eating heartily, the diarrhea had abated and constant improvement was recorded. There appears to be an early and real improvement with no untoward effects from the administration.

\section{SODIUM CACODYLATE IN TERTIARY SYPHILIS}

\section{REPORT OF A CASE *}

\section{W. CRIGLER, M.D.} NEW YORK

As comparatively few cases of tertiary syphilis treated with sodium cacodylate have been reported, and as widespread interest has been awakened in the treatment of syphilis with arsenical compounds by Ehrlich's new discovery, I wish to report the following case :

History.-J. L., aged 27 , presented himself for examination and treatment at the Manhattan Eye and Ear Hospital Sept. 28,1910 , complaining of faucial irritation, for which he sought relief. He was referred to the throat department, where he was examined, and the following history obtained: About

* Read before the Ophthalmological Section of the New York Academy of Medicine, Nov. 21, 1910 .
June 15 an indurated sore developed on the glans penis just back of the corona, followed in a few days by other sores on the body of the penis. Four weeks later there developed the eruption, followed by the faucial irritation from which he sought relief.

Examination.-The posterior pharyngeal wall was found ulcerated with two or three deep-seated ulcers on the buccal mucous membrane. The skin over the body showed numerous large and small rupial ulcers in various stages of development and necrosis. The patient stated positively that he bad never had any other lesion previous to the one reported as occurring ten weeks previously.

Treatment.-A diagnosis of rupial syphilis was made with tertiary manifestations in the throat, and the patient put on bi-weekly injections of salicylate of mercury, together with suitable means for the relief of the local irritation.

Transfer to Eye Department.-After about four weeks' treatment the man was no better, and owing to the fact that a large rupia had developed on the right upper evelid, with the possibility of its destruction, the patient was transferred to the eye department, where I first saw him on October 19. The diagnosis of rupial syphilis was confirmed by several of my colleagues, and in spite of the fact that the patient had had repeated injections of mercury, the Wassermann reaction was taken and found to be positive. The gumma in the lid was progressive.

Sodium Cacodylate Treatment.-The patient was put on daily injections of sodium cacodylate, $3 / 4$ grain to a dose. Within forty-eight hours the surface of the ulcer was smooth and healthy in appearance, the slough having been dissected away. At the end of one week the lid had entirely healed with very little deformity, considering the size of the slough, With the exception of two or three of the larger foci situated on subcutaneous bone surfaces near the skin and elbow, there was rapid cicatrization and healing of the ulcers. At the end of one week the injections were discontinued for a week, at the end of which time a second Wassermann test was negative. The treatment was then resumed in $11 \%$ gr. doses daily for one week longer, after which the man received three injections weekly till November 2l,

No internal medication was given until the reaction became negative, when strychnin and jron were given in tonic doses, three times a day. The patient has in no way suffered from the administration of arsenic. The case was apparently a very malignant one. It is possible that some lasting effect of the disease will continue to manifest itself owing to the destructive action of some hidden lesion, and since there are already numerous reports of recurrences after the use of salvarsan, it is not likely that the treatment in this case will completely eradicate the disease. In view of the fact, however, of the non-toxicity of sodium cacodylate, the simplicity of administration, and the rapidity with which it seems to arrest progressive lesions, it should be given whenever the proper administration of salvarsan cannot be carried out.

I hope to be able to report the future progress of this patient at a later date.

57 West Fifty-Eighth Street.

The Anesthetist.-An expert anesthetist is quick to note every change, and can so "nurse" his patient that it is seldom he has any anxiety from the appearance of untoward symptoms. These difficulties may turn up in the hands of the less experienced, who must at times give an anesthetic, and who must, therefore, get the most thorough training possible. No man can have confidence in his power to administer an anesthetic safely who has not a very clear idea as to what constitutes a danger signal and a definite knowledge of how to proceed instantly and without hesitation to get his patient into a safer condition.-W. Rankin, in the Practitioner. 